\title{
Assessment of ancient masonry slender towers under seismic loading: dynamic characterization of the Cuatrovitas tower
}

\author{
P. Pineda \& A. Sáez \\ Department of Continuum Mechanics and Structural Analysis, \\ School of Architecture, University of Seville, Spain
}

\begin{abstract}
The Cuatrovitas tower is a XIIth century almohad minaret located in the province of Seville (Spain) and it is considered the best preserved almohad religious building in the Iberian Peninsula. As it is placed in a seismic area, it is crucial for its preservation to evaluate its dynamic response under earthquake loading and to assess the safety level in its present state of conservation. In this paper a number of three-dimensional linear and non-linear finite element models with different levels of complexity and simplifications are developed, using 3-D solid elements or 3-D beams elements. All the models assume that the masonry structure is homogeneous and the material non-linear behaviour - including crushing and cracking - is simulated by means of different constitutive models. Subsequent non-linear static and non-linear dynamic analyses are performed. Previous static and time-history dynamic analyses with a simplified elastic material model are evaluated to calibrate the non-linear response, and to take into account that crack opening may introduce numerical instabilities. Comparison among the different models is thoroughly discussed, in particular as predicted local and global collapse mechanisms are concerned, in order to evaluate the suitability, accuracy and limitations of each analysis. To conclude, a general methodology is proposed to assess safety and to improve seismic resistance of this and other similar cultural heritage buildings.
\end{abstract}

Keywords: ancient masonry tower, almohad architecture, non-linear dynamic analysis, earthquake loading. 


\section{Introduction}

Historic masonry towers placed in seismically active regions could be severely damaged by earthquakes. Indeed, these structures are able to resist gravitational actions, but as they were not explicitly designed to withstand seismic effects, they show particularly weakness with regard to horizontal loadings induced by dynamic excitations. The high vulnerability of these constructions under horizontal actions is mostly due to the absence of adequate structural connections, which leads to overturning collapse [1]. Regarding Almohad minars, they are medieval towers of a type that is prone to suffer damages under earthquakes, mainly due to their slenderness, low shear strength and low ductility. Moreover, their possible lack of effective connections among structural elements - core, vaults and external walls - needs to be evaluated. Due to these reasons, it is crucial for their preservation to assess seismic safety in order to evaluate their dynamic response and, if necessary, to improve their structural strength. Indeed, prevention and rehabilitation can be successfully achieved only if diagnosis of the building is carefully analysed [2].

It is well known that analysis and evaluation of seismic reliability of masonry cultural heritage buildings is a difficult task, owing to uncertainties that mainly affect structural behaviour and mechanical material properties. The former includes lack of information on model definition - geometry, constraints, materials, constructive details.- and the latter is focused on non-linear masonry behaviour and low tensile strength. Furthermore, if a comprehensive study of structural behaviour is going to be performed, accuracy and suitability of the analytical or numerical method selected are essential issues.

A contribution to dynamic characterization, lateral capacity and seismic assessment of Almohad minarets is provided in a single case study, revealing advantages or disadvantages of different numerical analyses - static, modal, linear transient, non-linear transient and non-linear static. Simplified and detailed models based on the Finite Element Method are performed, and brittle non-linear behaviour of masonry is considered at the macro-level.

This research aims at predicting local and global collapse mechanisms, thus developing an accurate and practical method of analysis of dynamic response in Almohad constructions.

\section{Historical survey}

The Cuatrovitas medieval tower is a XIIth century minaret located in Bollullos de la Mitación, in the province of Seville, Spain, and nowadays it is part of the Nuestra Señora de Cuatrovitas Church, fig. 1. Furthermore, it is considered the best preserved Almohad religious construction erected in the Iberian Peninsula, and due to its proportions, sobriety and decoration it is a masterpiece of its architectonical style.

Minars were introduced at the end of the second century of Islam in Abbasid Mesopotamia. They were attached to a mosque in order to signify the acceptation degree of the religious edifice as an institution in Islamic society. In Almohad 


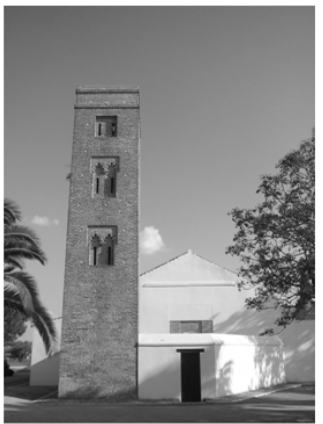

a

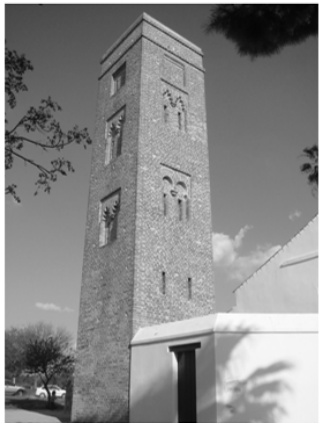

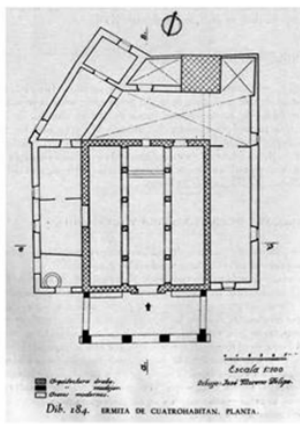

b

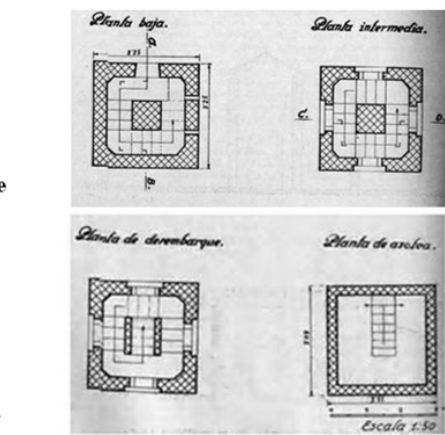

Figure 1: (a) General frontal view, and North and west façades; (b) Church plan section; (c) tower longitudinal section; (d) tower plan section. (Source: Catálogo arqueológico de la provincia de Sevilla.)

times, mosque towers had symbolic function too, since they were conceived as architectural statements of Islam during the Christian Reconquest of Spain. The first of the great minarets of this period, the Kutubiyya tower, was erected in 1158 in Marrakesh, Morocco, at the left end of the quibla wall of the mosque. When Seville became the Iberian capital of Almohads, the tower of its great mosque was constructed by Ahmad ibn Basu in 1184 on orders from Abu Ya'qub Yusuf. Unfortunately, the last of the more significant minars belonging to this epoch, the tower at the mosque of Hassan at Rabat, is unfinished. In this historical context the analysed minaret was built. Although not mentioned in any sources, the minar has been dated in $1175-1180$ by stylistic studies [3]. Comparison with the aforementioned towers suggests that the Cuatrovitas Minaret has similar shape and style of decoration. Besides, all of them are located in active seismic areas. These monuments are essential in evolution of Islamic religious architecture as they were models for minarets built in the metropolitan centres of the Maghreb until Ottoman times [4].

As a reference of the value of the monument studied in this work, it is important to mention that it has been inscribed in the Spanish Heritage Monument Listing since 1931. 


\section{Geometrical and structural survey}

The Cuatrovitas minaret is a free-standing tower situated next to the north façade of the church, walling in the shan- the original mosque court-. This relevant architectural monument is of moderate size, $3.25 * 3.25 \mathrm{~m}^{2}$ in lower plan, $3.10 * 3.10 \mathrm{~m}^{2}$ in upper plan and it rises $14.8 \mathrm{~m}$ above the current ground level. Its plan-height relation is $1 / 4.21$, complying with Almohad slenderness canons. The façade is decorated with rectangular panels and dual blind arches - five-foiled or horseshoe arches - framing small openings along the external walls, as it is in the nature of the purest Unitarian style.

Morphologically, the minaret is divisible into three structural parts: external walls, central core and barrel vaults, fig. 1. The average thickness of walls is $0.425 \mathrm{~m}$, core cross-section is $0.90 * 0.90 \mathrm{~m}^{2}$ and barrel vaults cross section is $0.14 \mathrm{~m}$. The inner chamber consists of an anticlockwise staircase covered by horizontal barrel vaults, which ascend around the square central solid core. The whole structure is built of clay bricks and lime mortar joints, originally covered with painted plaster. The aforementioned building materials are essential in Islamic Andalusian constructions. Brick average size is $0.28 * 0.14 * 0.045 \mathrm{~m}^{3}$ and average lime thickness is $0.035 \mathrm{~m}$. A careful visual survey of the structure revealed irregular mortar-brick disposition in several zones, where bricks were substituted by mortar, fig. 2. Moreover the tower only exhibits superficial cracks. No information on the character of the foundation is available, but the structure is supposed to be embedded in the soil. To conclude it is important to mention that no severe damage is observed.

For a complete report on this building refer to [3]. In addition, a comprehensive survey of the archaeological features can be found in [5].
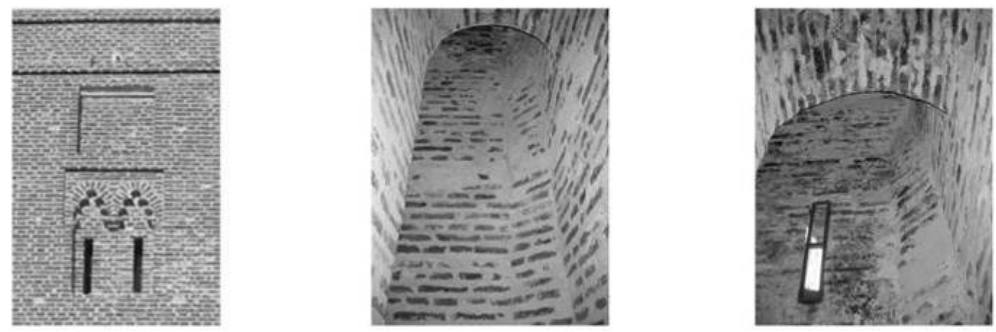

Figure 2: $\quad$ Aspects of the irregular mortar-brick disposition.

\section{Static analysis}

\subsection{Static analysis with linear material}

The first analysis carried out focused on static assessment of the detailed threedimensional finite element model, which allows one to consider accurately all the essential structural features. The ANSYS finite element software was used to construct the model, and three-dimensional eight node solid elements, 

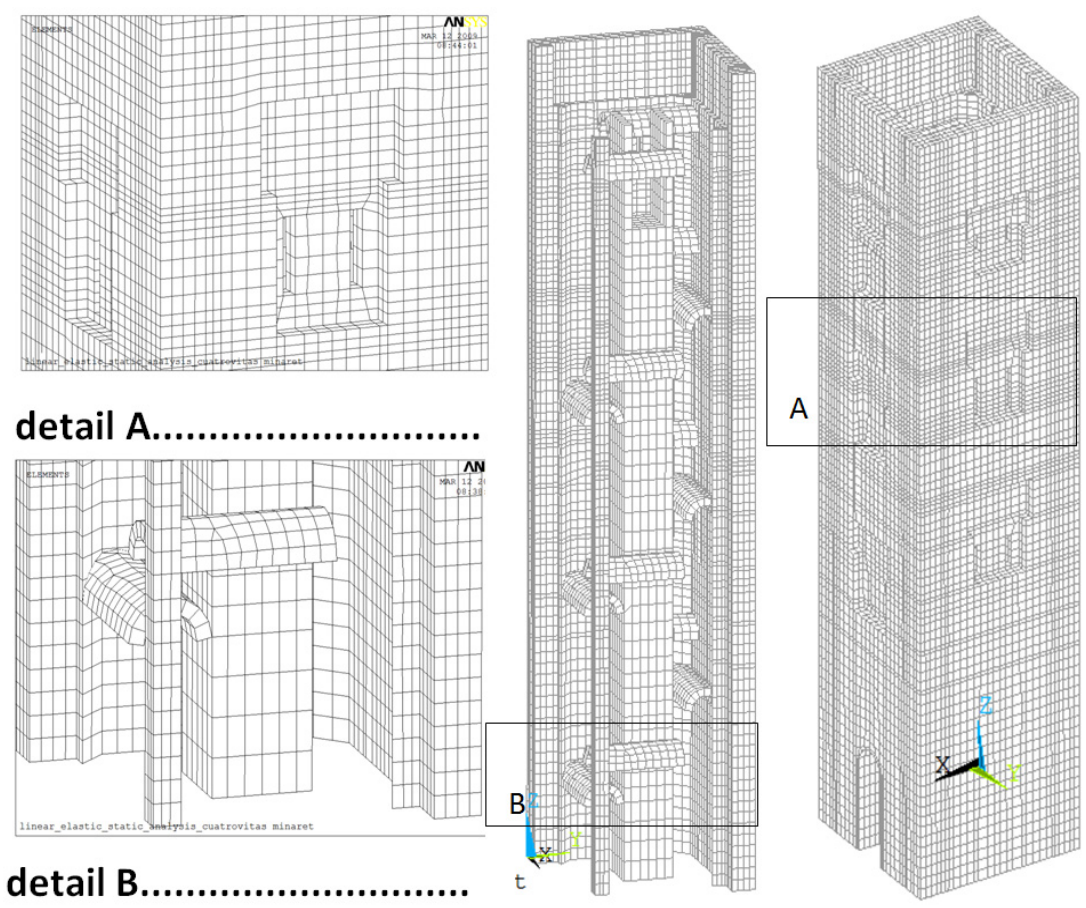

Figure 3: $\quad$ Finite Element model mesh.

SOLID 45, were employed for masonry material [6]. The mesh consists of 65,152 elements, 52,188 nodes and 154,956 active degrees of freedom; average element size is $0.11 \mathrm{~m}$. The wall thickness was discretized with four elements. This model comprises the most significant structural parts, namely real loadbearing wall thickness - replicating the rectangular panels framing openings, which reduce the average cross section - openings, vaults and central core, fig. 3 . The staircase self-weight was applied on the vaults, due to its constructive features. No information regarding physical material properties is available, thus the properties of contemporary structures in the region with the Cuatrovitas minar were considered [7]. Furthermore, a smeared model with homogenized properties was performed, and its linear elastic material properties were assumed as Young modulus $\mathrm{E}=1 \mathrm{GPa}$, Poisson ratio $v=0.2$, and specific weight $\mathrm{w}=17,000 \mathrm{~N} / \mathrm{m}^{3}$.

With regards to boundary conditions, the base of the tower was considered as completely constrained and contribution of the adjoining church was assumed to be negligible.

This preliminary study provides valuable information both on global behaviour and on interaction among the structural parts. Indeed, the analysis of the structure under gravity loading yields significant data, such as stress distribution, weak elements of potential failure and displacements, table 1. 
From the static numerical approach it may be observed that maximum compression level $-0.45 \mathrm{Mpa}$ - was reached by the basement, as expected, whereas maximum tensile stresses $-0.17 \mathrm{MPa}-$ appeared in the vaults. Furthermore, high stress concentrations were obtained in the connections among structural parts. The compressive stresses are admissible, but as stresses higher than tensile strength were obtained, the use of non-linear material is advisable. Furthermore, those results allow one to conclude that connections between vaults and walls are confirmed to be a vulnerable part of the building. With regard to displacements, the maximum horizontal values were reached by the vaults and the core.

\subsection{Static analysis with non-linear material}

A second static analysis was performed on the same detailed three-dimensional finite element model, taking into account the material non-linear behaviour. The Drucker-Prager perfectly plastic criterion [8] and the Willam-Warncke failure surface [9] were employed in the model. It is important to mention that those criteria provide neither stiffness degradation of brittle material caused by successive plastic deformation, nor cracks resulting from low cycle fatigue [10, 11]. However, both theories yield accurate results on three-dimensional solid models, in particular when predicted cracking progression is concerned. Furthermore, the previous static analysis and the following non-linear analysis show that either crushing or plastic deformation due to high compressive levels were not found in the analysed structure. Prior literature on masonry structural analysis $[10,12-14]$ has used those criteria in order to determine the frontier between linear and non-linear behaviour.

Three-dimensional eight-noded solid isoparametric element, SOLID 65, was employed to model the brittle material. The element is capable of cracking in tension - in three orthogonal directions - and crushing in compression. The masonry was assumed to be initially isotropic, until either one of the tensile or the compressive strength was exceeded. When cracking occurred, it was modeled through an adjustment of material properties which effectively treats the cracking as a "smeared band" of cracks. The stress-strain matrix was adjusted by introducing a plane of weakness in a direction normal to the crack face, and two shear transfer coefficients for open and closed cracks, $\beta_{\mathrm{t}}=0.15$ and $\beta_{\mathrm{c}}=0.75$ were considered. The $\beta_{\mathrm{t}}$ represents a shear strength reduction factor for those subsequent loads which induce sliding -shear - across the crack face. If crushing occurs, the complete deterioration of the structural integrity of the material is considered, and contribution to the stiffness of an element at the integration point is ignored.

The failure criterion was defined by means of two uniaxial strengths, namely uniaxial compressive strength, $f_{c}$, and uniaxial tensile strength, $f_{t}$. A parameter variation study of results concerning the uniaxial tensile strength as a percentage of the compressive strength was performed. The value thus selected was consistent with the present conservation state. With regard to the Drucker-Prager parameters, the expressions proposed by Lourenço [15] were considered, as shown in table 2. 
Table 1: $\quad$ Static analysis results.

\begin{tabular}{cccccc}
\hline \multicolumn{7}{c}{ static analysis results } \\
\hline material & $\mathrm{u}_{\mathrm{x}}(\mathrm{m})$ & $\mathrm{u}_{\mathrm{y}}(\mathrm{m})$ & $\mathrm{u}_{\mathrm{z}}(\mathrm{m})$ & $\mathrm{S} 1(\mathrm{MPa})$ & $\mathrm{S} 3(\mathrm{MPa})$ \\
\hline linear material & $0.67 \mathrm{E}-3$ & $0.23 \mathrm{E}-3$ & 0.0025 & 0.17 (tensile) & -0.45 (compressive) \\
\hline non-linear material & $0.68 \mathrm{E}-3$ & $0.23 \mathrm{E}-3$ & 0.0026 & 0.17 (tensile) & -0.36 (compressive) \\
\hline
\end{tabular}

Table 2: $\quad$ Model calibrating parameters.

\begin{tabular}{|c|c|c|c|c|c|}
\hline \multirow{3}{*}{ Parameter } & \multicolumn{5}{|c|}{ model calibrating parameters } \\
\hline & \multicolumn{5}{|c|}{ material criteria } \\
\hline & elastic & $\begin{array}{l}\text { Drucker- } \\
\text { Prager }\end{array}$ & $\begin{array}{l}\text { Willam- } \\
\text { Warncke }\end{array}$ & Nonlinear cc & trilinear \\
\hline Young Modulus, E (Pa) & 1E9 & & & 1E9 & \\
\hline Poisson ratio, $v$ & 0.2 & & & 0.2 & 0.2 \\
\hline Specific weigth, w (N/m3) & 17,000 & & & 17,000 & 17,000 \\
\hline Shear transfer coefficient $\beta t$ & & & 0.15 & & \\
\hline Shear transfer coefficient $\beta c$ & & & 0.75 & & \\
\hline $\begin{array}{l}\text { Compressive strength, fc } \\
\text { (Pa) }\end{array}$ & & & 1E6 & 1E6 & $1 E 6$ \\
\hline Tensile strength, $\mathrm{ft}(\mathbf{P a})$ & & & 1E5 & 1E5 & \\
\hline $\begin{array}{l}\text { Strain at peak stress, } \varepsilon \\
(\mathrm{m} / \mathrm{m})\end{array}$ & & & & 0.002 & \\
\hline Confinement & & & & 1 & \\
\hline Initial stiffness, $\mathrm{E}_{0}(\mathrm{~Pa})$ & & & & & 1E9 \\
\hline Post-peak stiffness, $\mathrm{E}_{\mathrm{f}}(\mathrm{Pa})$ & & & & & $-1 E 8$ \\
\hline Residual strength, $f R(P a)$ & & & & & 1E5 \\
\hline Cohesion (Pa) & & $1.5 \mathrm{E} 5$ & & & \\
\hline Internal friction & & $54^{\circ}$ & & & \\
\hline Dilatancy & & $10^{\circ}$ & & & \\
\hline
\end{tabular}

The results thus obtained were consistent with the linear analysis. Maximum compressive stresses $-0.36 \mathrm{Mpa}$ - were reached by the basement, as expected. Maximum tensile stresses $-0.17 \mathrm{Mpa}$ - appeared in the vaults, top level of the core and windows, as well as, high stress concentrations were obtained in the connections among structural parts. The compressive stresses are admissible, but stresses higher than tensile strength caused cracks, as fig. 4 shows. With regard to displacements, the maximum horizontal values were reached by the vaults and the core.

\section{Modal analysis}

A modal analysis was computed on the aforementioned refined elastic threedimensional finite element model, in order to obtain the dynamic properties natural frequencies, $\omega_{n}$, and modal shapes, $\zeta_{n}-$ and to serve as a starting point for the transient dynamic analysis. Damping was not taken into account. The sum of the effective modal masses for the considered modes is more than the $90 \%$ of the total mass-133,208.49 kg-. All these modes have an effective mass greater than $5 \%$ of the total mass. The first 4 modal shapes are provided in fig. 5 and the modal participating mass ratios for each principal direction are reported in table 3 . 


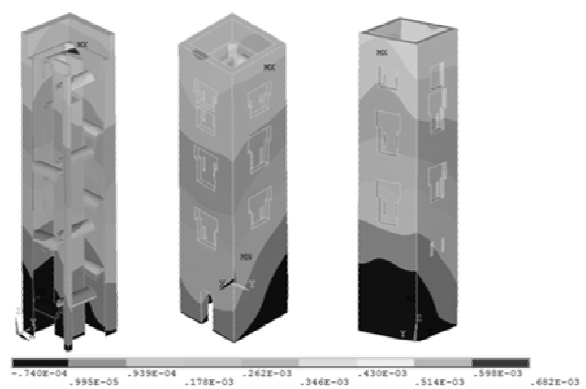

$u_{x}$ displacement static analysis, non-linear material

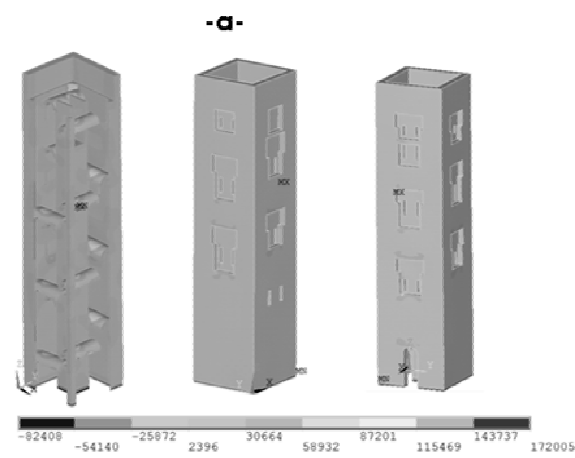

$S_{1}(P a)$ static analysis, non-linear material

$-c-$

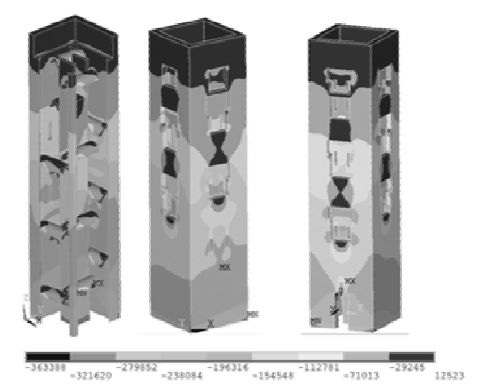

$S_{3}(\mathrm{~Pa})$ static analysis, non-linear material

-b-

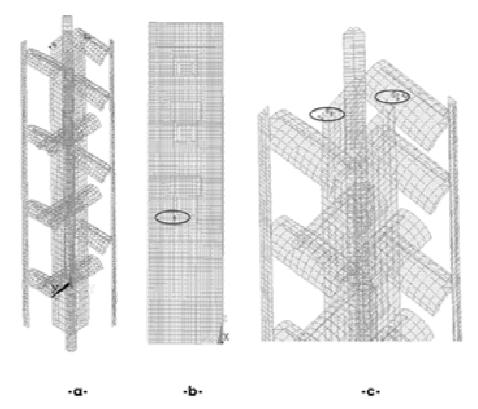

Crack pattern, (a) inside chamber, (b)north façade

(c) vault detail

-d-

Figure 4: Static analysis with non-linear material results.

From the eigenvalue analysis results, it may be concluded that the first and the second modal shapes provide the highest mass contribution, and both of them involves global bending. Those shapes are characterised by a high global stiffness and a monolithic behaviour among vaults, central core and walls. The third modal shape displays torsional response, and, when higher shapes are analysed, weak collaboration among the different structural parts is revealed, and significant out-of-plane deformations are observed.

The results thus obtained are consistent with the structural type, as it is characterised by two stiff elements - perimeter walls and core - connected by more flexible elements -barrel vaults-.

\section{Seismic analysis}

A number of three-dimensional linear and non-linear finite element models were developed, using 3-D solid elements or 3-D beams elements. All the models assume that the masonry structure is homogeneous and in order to consider the material non-linear behaviour - including crushing and cracking - different constitutive models were used. Furthermore, beam models took into account the structural response under cyclic loading. These analyses yielded significant 
Table 3: $\quad$ Effective modal masses.

\begin{tabular}{|c|c|c|c|c|c|}
\hline Mode & $\begin{array}{c}\text { Period } \\
\text { (S) }\end{array}$ & $\begin{array}{c}\text { Frequency } \\
\text { (Hertz) }\end{array}$ & $\begin{array}{c}\text { Effective } \\
\text { mass } x \\
\text { direction }^{*}(\mathrm{~kg})\end{array}$ & $\begin{array}{c}\text { Effective } \\
\text { mass y } \\
\text { direction }{ }^{*}(\mathrm{~kg})\end{array}$ & $\begin{array}{c}\text { Effective } \\
\text { mass z } \\
\text { direction }{ }^{*}(\mathrm{~kg})\end{array}$ \\
\hline 1 & 0.49 & 2.05 & 80410.5 & 2.91975 & 2.50050 \\
\hline 2 & 0.48 & 2.09 & 2.76858 & 81625.4 & $0.134283 \mathrm{E}-1$ \\
\hline 3 & 0.15 & 6.82 & 15.1173 & 1040.00 & $0.961566 \mathrm{E}-1$ \\
\hline 4 & 0.12 & 8.53 & 1.36813 & 28428.9 & 4.01811 \\
\hline 5 & 0.11 & 8.82 & 28259.5 & $0.292487 E-1$ & 12.2214 \\
\hline 6 & 0.08 & 11.95 & 41.2666 & 9.14584 & 30.9422 \\
\hline 7 & 0.07 & 13.17 & 15.0521 & 2.22816 & 93431.8 \\
\hline 8 & 0.07 & 14.14 & 656.086 & 1084.06 & 513.403 \\
\hline 9 & 0.07 & 14.43 & 71.6396 & 15.5072 & 11306.4 \\
\hline 10 & 0.06 & 15.09 & 961.888 & 1827.76 & 150.233 \\
\hline 11 & 0.06 & 16.57 & 300.605 & 60.4455 & 18.2308 \\
\hline 12 & 0.06 & 16.67 & 47.5473 & 8.36312 & 0.141486 \\
\hline 13 & 0.06 & 16.79 & 121.263 & 16.0208 & 0.525862 \\
\hline 14 & 0.06 & 17.27 & 252.967 & 1108.26 & 0.792379 \\
\hline 15 & 0.06 & 17.67 & 1458.99 & 2553.17 & 0.139824 \\
\hline 16 & 0.05 & 18.10 & 3228.51 & 276.509 & 1.02579 \\
\hline 17 & 0.05 & 19.16 & 5.58691 & 367.799 & $0.442064 \mathrm{E}-1$ \\
\hline 18 & 0.05 & 19.53 & 12.9383 & 13.6242 & 0.769535 \\
\hline 19 & 0.05 & 20.58 & 11.3614 & 1684.52 & 0.301165 \\
\hline 20 & 0.05 & 21.14 & 1840.22 & 0.793902 & 2.52932 \\
\hline \multicolumn{3}{|c|}{$\begin{array}{l}\text { *x direction: parallelto east and } \\
\text { west façades. } \\
\text { y direction: parallel to north and } \\
\text { south façades. } \\
\text { z direction: parallel to longitudinal } \\
\text { axis }\end{array}$} & $\Sigma \mathrm{Meff}=117,715$ & $\begin{array}{l}\sum \text { Meff= } \\
120,126\end{array}$ & $\begin{array}{c}\sum \text { Meff }= \\
105,476\end{array}$ \\
\hline
\end{tabular}
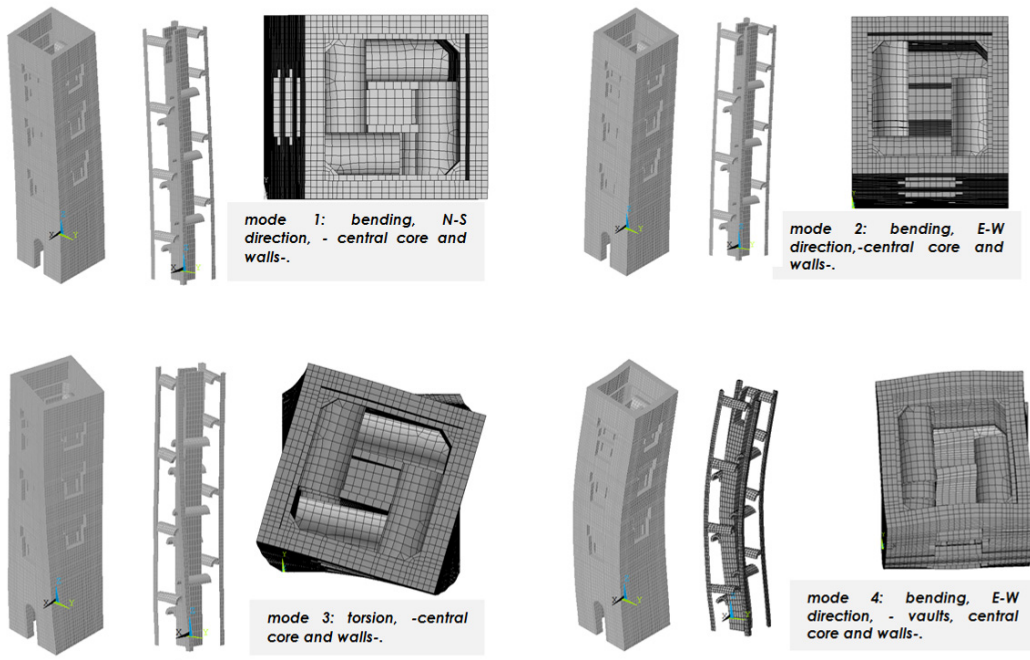

Figure 5: $\quad$ Modal shapes.

information on the local and global collapse mechanism predictions. Previous time-history dynamic analyses are evaluated to calibrate the non-linear response, and to take into account that crack opening may introduce numerical instabilities. 


\subsection{Seismic action}

The Cuatrovitas tower is placed in a seismic area, and the value of the peak ground acceleration is $0.07 \mathrm{~g}$ according to the Spanish Seismic Standard [16]. Five synthetic accelerograms were generated following the proposed method by Gasparini and Vanmarcke [17].Those ground acceleration time-histories are compatible with the Eurocode 8 [18] horizontal and vertical design spectra. The type 2 elastic response parameters, for a ground type $\mathrm{C}$, were adopted. The stationary part duration was equal to $10 \mathrm{~s}$ and the total duration was equal to 20 s, fig. 6. Modelling of seismic action was achieved by introducing three simultaneously acting synthetic accelerograms at the basement, which were applied at each structural principal axis. The time-dependent structural response was obtained from 5 nonlinear time-history analyses, following the component combinations proposed by EC8.

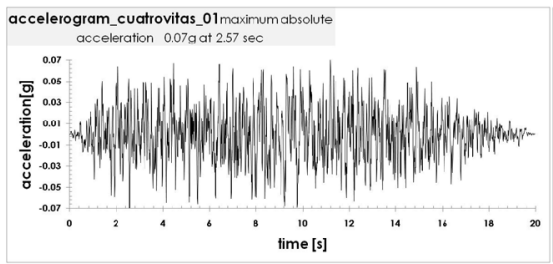

a

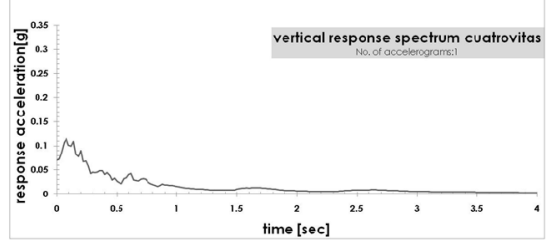

$\mathbf{c}$

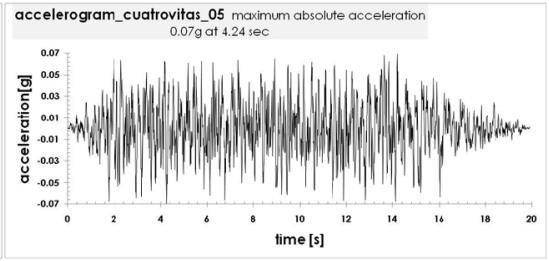

b

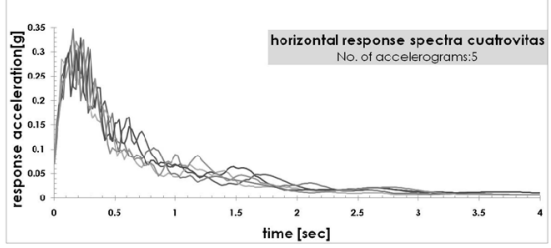

d

Figure 6: Seismic action.

\subsection{Non-linear dynamic analysis of simplified beam models}

Simplified 3-D beam models were used to predict the nonlinear inelastic response of the tower subjected to the seismic loading. Due to the geometrical properties, the component combination applied was: $0.30 \mathrm{E}_{\mathrm{Edx}}+\mathrm{E}_{\mathrm{Edy}}+\mathrm{E}_{\mathrm{Edz}}$, where, $E_{E d x}, E_{E d y}$ and $E_{E d z}$ represent the action effect due to the application of the horizontal and vertical component of the design seismic action.

The direct integration of the motion equations was accomplished using the Newmark algorithm [19]. The ANSYS and SeismoStruct [20] F.E. software were used to construct the models. The BEAM4 ANSYS element and the 3-D Inelastic Frame beam-column SeismoStruct element were used. Cantilever beam models, comprised of the central solid core, were performed in order to obtain an upper limit response. Other recent research works have considered structural 
parts as perfectly merged in beams models in order to obtain lower limit response [21]. The analysed tower mesh consists of 15 elements and 16 nodes. The node position is the same that the vaults position. Modelling of non-linear material behaviour is achieved by means of different constitutive models, namely, a uniaxial nonlinear constant confinement model, and a simplified uniaxial trilinear concrete model.

The former follows the constitutive relationship proposed by Mander et al. [22] and the cyclic rules proposed by Martinez-Rueda and Elnashai [23]. This is a cyclic stress-strain model for both confined and unconfined brittle materials, and it is able to provide a good estimation of the cyclic response of structures dominated by flexure and axial force under static and dynamic conditions. The specific model calibrating parameters used to fully describe the mechanical characteristics of this model were: compressive strength $f_{c}$, tensile strength $f_{t}$, strain at peak stress $\varepsilon$, confinement factor $\mathrm{k}_{\mathrm{c}}$, specific weight $\mathrm{w}$, Young modulus E, and Poisson ratio $v$, see table 2. This approach allowed to cope with the structural response under cyclic loading, taking into account inelastic strain and degradation of strength and stiffness.

The latter model assumes no resistance to tension and features a residual strength plateau. The specific model calibrating parameters used to describe the mechanical material properties were: compressive strength $f_{c 1}$, initial stiffness $E_{1}$, post-peak stiffness $E_{2}$, residual strength $f_{c 2}$, specific weight $w$, Young modulus E, and Poisson ratio $v$, see table 2.

A Rayleigh model for damping was assumed, that is:

$$
c=a_{0} m+a_{1} k ; \quad a_{0}=\zeta \frac{2 \omega_{i} \omega_{j}}{\omega_{i}+\omega_{j}} \quad a_{1}=\zeta \frac{2}{\omega_{i}+\omega_{j}}
$$

where $c, m$ and $k$ are the damping, mass and stiffness matrices, respectively. The two modes $i$ and $j$ were assumed to have the same damping ratio equal to $3 \%$. That ratio is a recommended value for unreinforced masonry structures [24].The modes considered are the first one and the second one, as they contributed significantly to the response. The first natural frequency $\omega_{1}$ was equal to 3.73 $\mathrm{rad} / \mathrm{sec}$ and the second natural frequency $\omega_{2}$ was equal to $23.4 \mathrm{rad} / \mathrm{sec}$. According to (1) the coefficients $\mathrm{a}_{0}$ equal to 0.19 and $\mathrm{a}_{1}$ equal to 0.002 were obtained.

Those simplified models provided relevant information when global collapse mechanisms such us the tower over-turning were analyzed. The solid central core is safe if, for each time step the response eccentricity is minor than the eccentricity of the normal force producing the over-turning. After analysing efforts and displacements it may be concluded that the tower is stable under this earthquake loading, fig. 7.

\subsection{Non-linear dynamic analysis of detailed 3-D solid model}

Additional dynamic time-history analysis was performed in order to predict the nonlinear inelastic response of the tower. The same 3-D F.E model as in section 4.2 was used. 


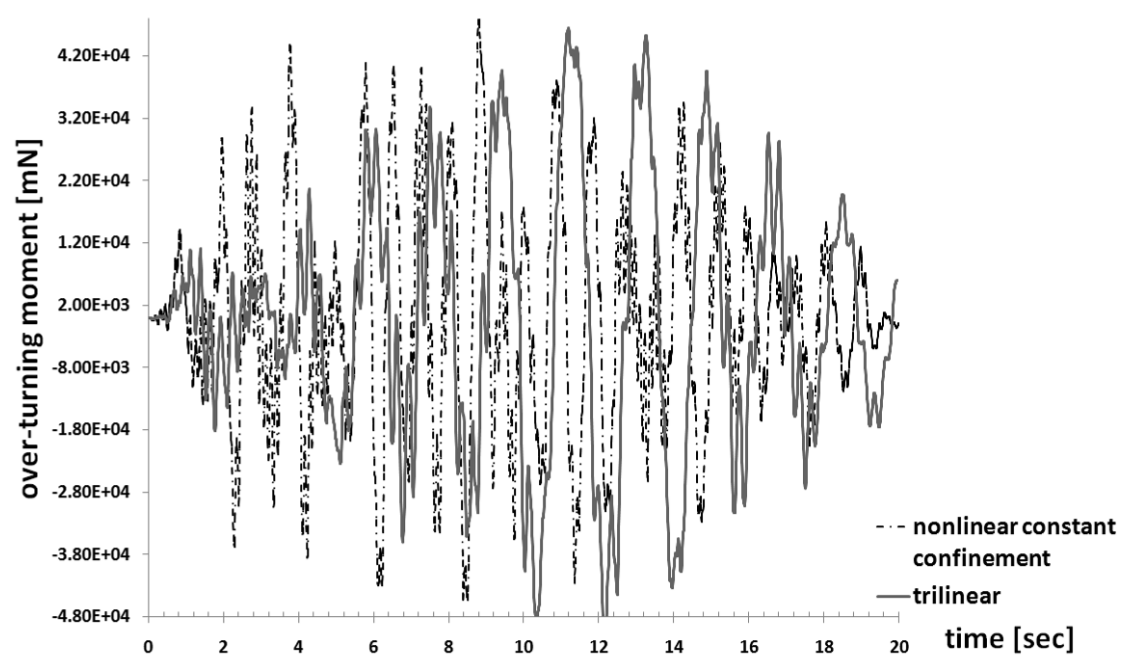

Figure 7: Over-turning assessment.

A Rayleigh model for damping-according to the previous modal analysis-was assumed, and the coefficients $\mathrm{a}_{0}$ equal to 0.69 and $\mathrm{a}_{1}$ equal to 0.0009 were applied. Two different materials were considered, namely the linear elastic material and the Drucker-Prager Willam-Warncke non-linear material. The results obtained show that the low tensile strength exhibited by masonry, leads to a higher cracking pattern than the static approach. The vaults, the framed small openings along the external walls, and the inside walls show signs of wear. The largest tensile stresses are reached in the connections of the barrel vaults with the inside walls and the central core. The maximum compressive stress is far below the compressive strength, and obviously, no crushing is expected. The displacement range is quite low, and no over-turning is caused. In spite of the dynamic input the structure exhibits a monolithic behaviour. The obtained results are provided in table 4 and the cracking patterns are reported in fig. 8 .

Table 4: Non-linear dynamic analysis results.

\begin{tabular}{ccccccc}
\hline \multicolumn{7}{c}{ transient analysis results: displacements } \\
\hline material & $\mathrm{u}_{\mathrm{x} \min }(\mathrm{m})$ & $\mathrm{u}_{\mathrm{x} \max }(\mathrm{m})$ & $\mathrm{u}_{\mathrm{ymin}}(\mathrm{m})$ & $\mathrm{u}_{\mathrm{ymax}}(\mathrm{m})$ & $\mathrm{u}_{\mathrm{zmin}}(\mathrm{m})$ & $\mathrm{u}_{z \max }(\mathrm{m})$ \\
\hline linear material & $-0.24 \mathrm{E}-3$ & $0.19 \mathrm{E}-3$ & -0.0017 & $-0.52 \mathrm{E}-4$ & -0.0025 & $0.78 \mathrm{E}-4$ \\
\hline non-linear material & -0.0035 & -0.0028 & -0.01 & -0.01 & -0.007 & -0.005 \\
\hline
\end{tabular}

\begin{tabular}{ccccc}
\hline \multicolumn{5}{c}{ transient analysis results: principal stresses } \\
\hline material & $\mathrm{S}_{1 \min }(\mathrm{MPa})$ & $\mathrm{S}_{1 \max }(\mathrm{MPa})$ & $\mathrm{S}_{\mathbf{3 m i n}_{\min }}(\mathrm{MPa})$ & $\mathrm{S}_{3 \max }(\mathrm{MPa})$ \\
\hline linear material & $\mathbf{0 . 1}($ compressive $)$ & 0.17 (tensile) & $\mathbf{0 . 5}$ (compressive) & $\mathbf{0 . 0 1 3 ( \text { tensile) }}$ \\
\hline non-linear material & $\mathbf{0 . 1}$ (compressive) & 0.19 (tensile) & $\mathbf{0 . 5 9}$ (compressive) & $\mathbf{0 . 0 1 5}$ (tensile) \\
\hline
\end{tabular}



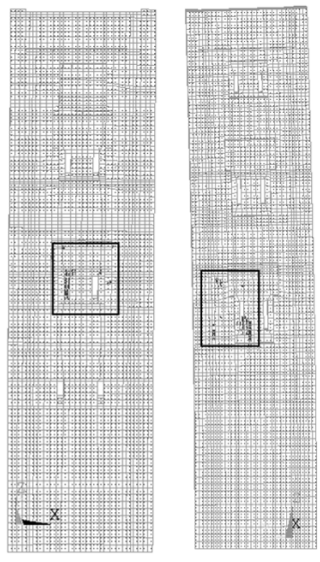

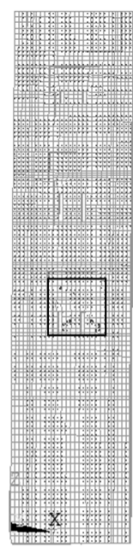

Figure 8: $\quad$ Cracking patterns.
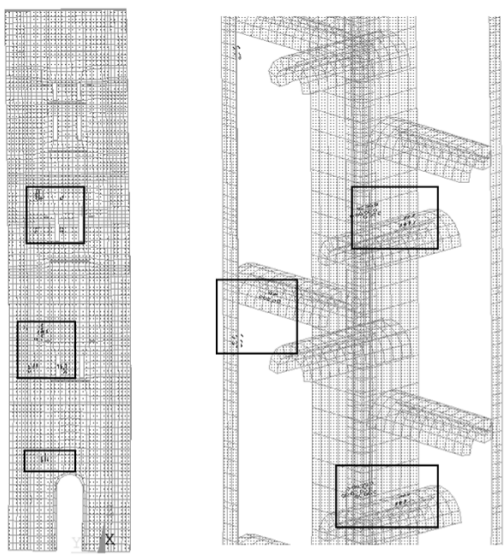

\section{Conclusions}

The Cuatrovitas medieval tower has been analysed under seismic loading, in order to assess its structural behaviour. For this purpose, a number of threedimensional linear and non-linear finite element models with different levels of complexity and simplifications were developed.

As a summary of the results, it may be concluded that static analyses, with linear and non-linear materials, provide relevant information regarding to interaction and stress distribution among structural parts. Furthermore, weak points which are prone to suffer damage under seismic loading may be identified -for instance, vaults, windows and connections-.

As far as the seismic transient analysis is concerned, it may be stated that the Drucker-Prager perfectly plastic criterion and the Willam-Warncke failure surface, are valuable tools in order to predict local failure - cracking progression - in a detailed 3-D F.E. model. Those criteria yield reliable results when neither crushing nor high plastic deformation due to high compressive are expected. Moreover, as the low tensile strength exhibited by the material yields in nonlinear behaviour, it is important to use a cracking capable constitutive model.

The simplified models allow to determine the upper boundary response - i.e. global collapse mechanisms such as tower over-turning-, taking into account the response under cyclic loading. Two constitutive models, namely, a uniaxial nonlinear constant confinement model, and simplified uniaxial trilinear concrete model were applied, and all of them provide significant data in good agreement.

The aforementioned methodology might be useful in order to assess safety and to improve seismic resistance of this and other similar cultural heritage buildings. 


\section{References}

[1] Lourenço, PB., \& Roque, JA., Simplified indexes for the seismic vulnerability of ancient masonry buildings. Construction and Building Materials, 20, pp. 200-208, 2006.

[2] Binda, L., Saisi, A., \& Tiraboschi, C. Investigation procedures for the diagnosis of historic masonries. Construction and Building Materials, 14, pp. 199-233, 2000.

[3] Gurriarán Daza, P., Acerca del alminar almohade de Cuatrovitas en Bollullos de la Mitación (Sevilla), Delegación de Cultura, Ayto. Bollullos de la Mitación. 2000.

[4] Bloom, J., Minaret, Symbol of Islam, Oxford Studies in Islamic Art VII, Oxford University Press, pp 99-125,1989.

[5] Valor Piechotta, M. Aún más sobre Cuatrovita: Análisis de sus fuentes documentales y prospección arqueológica. Estudios de Historia y Arqueología medieval, II, Cádiz, 1983.

[6] ANSYS, ANSYS Manual SET, ANSYS Inc., Southpoint, 275 Technology Drive, Canonsburg, PA 15317, USA, 1998.

[7] Barrios Padura, A., Estudio de las cimentaciones de edificios históricos en la provincia de Sevilla: siglo XII al XVI. Tesis Doctoral, Universidad de Sevilla, Departamento de Construcciones Arquitectónicas, 2001.(PhD Dissertation).

[8] Drucker, D.C., Prager, W. Soil mechanics and plastic analysis or limit design. Q Appl Math, 10, pp.157-16, 1952.

[9] Willam, K.J., Warncke, E.D. Constitutive model for the triaxial behaviour of concrete. Proceedings of the International Association for Bridge and Structural Engineering, 19. ISMES. Bergamo, Italy, 1975.

[10] Pallarés, F.J., Agüero, A., Ivorra, S., A comparison of different failure criteria in a numerical seismic assessment of an industrial brickwork chimney. Materials and Structures, 42, pp. 213-226 DOI 10.1617/s11527008-9379-5. 2009.

[11] Oliveira, D.V., Lourenço, P.B., Implementation and validation of a constitutive model for the cyclic behaviour of interface elements. Comput. Struct, 82, pp. 1451-1461,2004.

[12] Fanning, P.J., Boothby, T.E., Three-dimensional modelling and full-scale testing of stone arch bridges. Computers and Structures, 79, pp. 26452662, 2001.

[13] Bartoli, G., Betti, M., Spinelli, P., Tordini, B., An "innovative" procedure for assessing the seismic capacity of historical tall buildings: The "torre Grossa" masonry tower. Structural Analysis of Historical Constructions, New Delhi, 2006. P.B. Lourenço, P. Roca, C. Modena; S. Agrawal (Eds), ISBN 972-8692-27-7.

[14] Betti, M., Vignoli, A., Assessment of seismic resistance of a basilica-type church under earthquake loading: Modelling and analysis, Adv Eng Softw (2007), doi:10.1016/j.advengsoft.2007.01.004. 
[15] Lourenço, P.B., Computational strategies for masonry structures, Dissertation, Delft University of Technology, Delft, The Netherlands. 1996.

[16] Norma de Construcción Sismorresistente: Parte General y Edificación. NCSE-02, Ministerio de Fomento, (Spanish Standard). 2002.

[17] Gasparini, D.A., Vanmarcke, E.H., Simulated earthquake motions compatible with prescribed response spectra. Massachusetts Institute of Technology, Cambridge, Massachusetts, 1976.

[18] Eurocode 8. Design provisions for earthquake resistance of structures. Part 1-4: General rules - strengthening and repair of buildings. ENV 1998-1$4 ; 2004$.

[19] Newmark, N.M., A method of computation for structural dynamics. Journal of the Engineering Mechanics Division, ASCE, 85, No.EM3, pp.67-94., 1959.

[20] SeismoStruct [2007]. "SeismStruct -A computer program for static and dynamic nonlinear analysis of framed structures"[online]. Available from URL: http://www.seismosoft.com.

[21] Project Title: Improving the Seismic Resistance of Cultural Heritage Buildings, Project Contract $\mathrm{N}^{\circ}$ : ALA/95/23/2003/077-122, Title: Benchmarking on the seismic behaviour of the Qutb Minar, Project Beneficiary: Universidade Do Minho, Portugal. Asia-wide Programme: EU-India Economic Cross Cultural Programme, 2006.

[22] Mander, J.B., Priestley, M.J.N. and Park R., Theoretical stress-strain model for confined concrete. Journal of Structural Engineering, 114, No. 8, pp.1804-1826, 1988.

[23] Martinez-Rueda J.E and Elnashai A.S., Confined concrete model under cyclic load. Materials and Structures, 30, (197), pp.139-147, 1997.

[24] Chopra, A.K. Dynamics of structures: Theory and Applications to Earthquake Engineering, Prentice-Hall. 1995. 